\title{
Aula de educação física não é lugar de estudar o corpo!?
}

Silvane Fensterseifer Isse*

\begin{abstract}
Resumo: Este texto discute a compreensão de estudantes de Ensino Médio acerca das relações entre estudar o corpo e a educação física escolar. O estudo utilizou observações, entrevistas semi-estruturadas, diálogos e diário de campo como instrumentos para coleta de informações. Os resultados apontam que há uma dissociação entre educação física na escola e os estudos sobre o corpo. Estudar o corpo é relacionado às disciplinas de biologia e ciências e a intervenções de profissionais da saúde na escola. Há uma perspectiva biomédica, individualista e hierárquica em relação aos saberes do corpo, que é compreendido a partir de uma perspectiva anistórica, descontextualizada, disciplinar e fragmentada. Problematiza a ideia de que estudar o corpo está diretamente relacionado a aprender cuidados que o tornam saudável, relacionado muito mais às ciências da saúde do que à pedagogia.
\end{abstract}

Palavras-chave: Corpo. Conhecimento. Educação Física Escolar.

"Aula de Educação Física não é lugar de estudar o corpo": uma afirmação exclamativa e uma interrogação. Crença ou verdade para alguns, dúvida ou questionamento para outros. Certamente uma importante problemática para o campo da Educação Física Escolar.

\section{APRESENTANDO O CONTEXTO DA PESQUISA}

Este tex to baseia-se em questões que emergiram durante minha pesquisa de mestrado, realizado no Programa de Pós-Graduação em Ciências do Movimento Humano da Universidade Federal do Rio Grande do Sul. O estudo foi intitulado "Corpo e feminilidade: um estudo realizado com meninas adolescentes no contexto da Educação

\footnotetext{
*Centro Universitário Univates. Lajeado, RS, Brasil. E-mail: silvane@univates.br
} 
Física escolar" e teve como objetivo compreender as representações de feminilidade de meninas adolescentes e de que forma essas representações se associam ao corpo e às aulas de Educação Física. Foi realizado com estudantes do primeiro ano do Ensino Médio de uma instituição escolar pública estadual do município de Lajeado/ RS.

Os instrumentos utilizados para a coleta das informações foram observações, entrevistas semi-estruturadas, diálogos e diário de campo. O contexto das observações foi as aulas de Educação Física de um grupo de trinta meninas, estudantes do turno da manhã, residentes em diferentes bairros do município, bem como na zona rural de Lajeado, e em municípios vizinhos. As aulas, dois períodos de cinquenta minutos conjugados, eram realizadas uma vez por semana, no turno inverso às aulas das demais disciplinas, e foram observadas durante seis meses. As falas das meninas, que surgiram durante as aulas ou conversas informais que eram presenciadas por mim, foram registradas em diário de campo. Além disso, foram realizadas entrevistas, gravadas e posteriormente transcritas, com cinco meninas, que tinham entre quinze e dezesseis anos.

O foco principal da pesquisa não era a relação que as meninas estabeleciam entre aulas de educação física e processo de estudar o corpo, no entanto, a dissociação entre educação física e estudo do corpo apareceu fortemente nas falas das meninas, o que me causou certo estranhamento, inicialmente, e impulsionou a reflexão que faço a seguir.

\section{2 "NAS AULAS DE CIÊNCIAS QUE A GENTE APRENDEU A CONHECER O CORPO"}

Conhecer o corpo. Estudar o corpo. Como? Onde? Quando? Em que circunstâncias? De que forma? Com quais professores? Com quais fontes de informação? Com quais recursos didáticos? Entre as várias questões que foram apontadas nas falas das participantes do estudo está o fato de a maioria delas não ver nas aulas de Educação Física um espaço para estudar o corpo. Estudar 
o corpo ou refletir sobre ele, na escola, foi claramente relacionado às disciplinas de biologia e ciências ou a palestras com profissionais da saúde, como médicos, nutricionistas ou enfermeiros. Laura ${ }^{1}$, quinze anos, não hesitou ao colocar: "nas aulas de ciências que a gente aprendeu a conhecer o corpo". De que forma Laura construiu essa verdade?

Corpo - biologia - ciências - saúde - especialistas: uma perspectiva biomédica, individualista e hierárquica em relação aos saberes do corpo. O corpo de que Laura fala é o corpo que poderia ser conhecido pela sua anatomia, seu funcionamento, suas alterações morfológicas e fisiológicas, quando comparado às categorias, classificações, tabelas, gráficos ou desenhos produzidos pelos saberes das ciências "exatas". Corpo examinado. Corpo fragmentado. Matéria a ser desvendada em suas minúcias visíveis a olho nu ou através dos recursos tecnológicos. Corpo morto, "inerte, anistórico e descontextualizado da vida" (CECCIM; CARVALHO, 2005, p. 72). Corpo muitas vezes apartado de sua dinâmica, seus afetos e autorias. Corpo como "uma posse, um atributo, um outro". (LE BRETON, 2006, p. 10)

As meninas demonstravam interesse em estudar esse corpo do não movimento, da não relação, do isolamento, do não gênero, da não raça, da não geração, da não classe social... O corpo das páginas dos livros didáticos e das revistas femininas, das imagens e discursos das campanhas de saúde, das falas dos especialistas, das manchetes de jornais... "Um corpo que deixa de ser humano e passa a ser didático" (SANTOS, 2007, p. 89). O corpo desejado socialmente, o corpo que está fora do próprio corpo. Não é do corpo social ou cultural que se fala, mas do corpo individual, destituído de sua singularidade (DAOLIO, 1994), que se produz em função do autocuidado.

Esse tipo de interesse pelo corpo não parecia tratar-se exatamente de uma escolha das meninas, mas de uma restrição do olhar acerca do corpo. Estudar o corpo, pois, ia ganhando sentido à

${ }^{1}$ São usados nomes fictícios neste texto.

Movimento, Porto Alegre, v. 17, n. 02, p. 225-237, abr/jun de 2011. 
medida que se aprende os cuidados que o tornam "saudável". Tornálo saudável, por sua vez, é deixá-lo "limpinho", bem nutrido, bem exercitado, protegido de doenças ou gestações. "No ensino do corpo na escola, dão primazia ao estudo das doenças, da higiene, dos regimes de conduta [...] parece que se trata da saúde pelo lado inverso, pelo seu contraponto (a doença), criando uma pedagogia bastante comum e recorrente". (SANTOS, 2007, p. 81) A escola fala do corpo ideal, quando deveria falar do corpo real, do corpo possível, do corpo que circula pelos ambientes da vida, que não são perfeitos, que não são previsíveis, que não são lineares, que são, muitas vezes, "desregrados". Ensinar a viver na regra pode significar limitar as possibilidades de vida, e não ampliá-las.

A ideia de corpo saudável era fortemente associada pelas meninas à ausência de doenças ou mal-estar. $\mathrm{O}$ conceito ampliado de saúde parece não ter batido à porta da escola, ou a escola não o deixou entrar. Os imperativos de saúde (LUPTON, 2000), amplamente divulgados culturalmente (o que comer, quanto comer, quando comer, o que não comer, como se exercitar, com que frequência, com que intensidade, tomando quais cuidados, qual o melhor exercício físico, quais os cuidados para a prevenção da gravidez e de doenças sexualmente transmissíveis, etc) eram frequentemente mencionados como aprendizagens obtidas a respeito do corpo, na escola ou fora dela. Valorização de um corpo disiciplinado e bem comportado.

A crença de que o autocontrole, as restrições e a força de vontade pessoal são caminhos diretos para a boa saúde era incorporada pelas meninas, ou seja, a ideia de que não é saudável quem não quer constituía-se numa verdade para muitas delas. As limitações para se alcançar uma boa saúde, as quais se encontram para além do controle individual, como as características hereditárias, as características pessoais, o acesso a recursos, as redes sociais de apoio, o clima, os perigos naturais, a contaminação ambiental ou até mesmo a sorte não eram quase discutidas. (LUPTON, 2000)

Nessa perspectiva, estudar o corpo relaciona-se muito mais às Ciências da Saúde do que à Pedagogia. Estudar o corpo se constitui 
em apreender conceitos "científicos", em detrimento do compartilhamento de saberes, afetos, crenças, valores, medos, angústias que habitam os corpos escolares. Asensibilização do corpo, a plasticidade do corpo, o potencial criativo do corpo não são tomados como pautas de estudo do corpo. Isso tudo é muito complexo, isso tudo demanda muito tempo, isso tudo não segue critérios pré-fixados, isso tudo desestabiliza. Parece mais "prático" simplificar a existência corporal. Menos pedagogia e mais "ciência"!

O entendimento do corpo estava bastante relacionado a ideias desenvolvimentistas, evolutivas e à "interioridade do corpo, sua segmentação em órgãos, aparelhos, sistemas" (Santos, 2007, p.89), bem como a prescrições profiláticas e curativas de doenças, tão enfatizadas pelos estudos do corpo realizados desde o evento da ciência moderna. Formulações parciais sobre o corpo, análises mecanicistas e organicistas do corpo, práticas neutras para "salvar" o corpo. (CECCIM; CARVALHO, 2005)

Estudava bastante o corpo humano. Elas entravam bem nos assuntos. Falavam de cada parte do teu corpo, também o que tu achou diferente, como tu foi crescendo, o que tu achou que mudou no teu corpo [...] A gente começou a estudar isso (o corpo), e ela (a professora) pedia pra gente trazer tudo que fazia no dia, desde que acordava, o que fizemos, comemos, exercícios, tudo, tudo, tudo. Eu achava legal, porque eles acompanhavam todo teu dia. Diziam o que era importante fazer, o que a gente devia deixar de lado um pouco. Acho que é bem interessante isso. (fala de SARA, 16 anos).

Estudar o corpo, portanto, relaciona-se, principalmente, a como cuidar dele e desenvolver bons "habitus"2 (LUPTON, 2000, p. 22). Isso a educação física escolar geralmente não faz: ela ensina esportes e outras práticas corporais, portanto, não estuda o corpo!? Se estudar o corpo é falar da matéria que fica tão exposta a perigos externos e

\footnotetext{
2Segundo Deborah Lupton (2000, p .22), "Bourdieu (1990, p. 9-10) desenvolveu o conceito de habitus para lidar com o paradoxo de que as pessoas podem agir de certa maneira, visando a certos fins, sem estar conscientes destes fins, mas também sem estar sendo determinadas por eles".
} 
que precisa aprender a se proteger, se preservar, precisa-se de pessoas que saibam como fazer isso. Quem sabe como fazê-lo? Os especialistas da saúde!? Já que lês geralmente não fazem parte do grupo de professores e profissionais que trabalham na escola, estudar o corpo acaba se restringindo a eventos isolados, eventuais, pontuais, muitas vezes descontextualizados. Estudar o corpo parece ser mais uma obrigação, um mecanismo de controle do que uma aventura vivida na escola.

\section{3 "O CORPO É UMA COISA QUE TODO MUNDO TEM, QUE TENTA CUIDAR MUTTO PRA NÃO TER NADA DE ERRADO"}

Corpo como instrumento, máquina humana com características universais, compreendido e descrito a partir dos campos disciplinares que se preocupam em abordá-lo na escola. Corpo que não possui falta ou excesso. Corpo que busca a potência, a agilidade a habilidade, a resistência. Corpo que treina para alcançar ou manter a "normalidade". Corpo de boa produtividade. Corpo suficientemente saudável e funcional para realizar as tarefas cotidianas de forma "satisfatória".

$\mathrm{Eu}$ acho importante meu corpo porque eu posso caminhar, eu posso ver, falar, escrever... Essa é a importância que meu corpo tem pra mim. Não tem outra importância. Eu sou normal, eu como de tudo, sinto o gosto de tudo, essas coisas (fala de LAURA, 15 anos).

$\mathrm{O}$ corpo não tem muito significado. $\mathrm{O}$ corpo é uma coisa que todo mundo tem, que tenta cuidar muito pra não ter nada de errado. [...] Sem ele eu não faria nada, né? Porque ele me leva onde... Sem minhas pernas eu não poderia andar, sem meus braços eu não poderia escrever ou pegar as coisas ou, se eu fosse cega, eu não poderia olhar. Acho que o corpo pra mim é tudo, sem ele eu não faria nada (fala de MARTA, 16 anos).

Andar, ver, falar, escrever, comer, saborear, pegar - ações cotidianas que permitem levar a vida. Corpo que não tem muito 
significado e que, ao mesmo tempo, é tudo. "Coisa" que todo mundo tem. Algo que nos leva. Não somos nós mesmos nos transportando, mas um objeto externo a nós que nos carrega? Falar de ausência de significado seria falar de corpo matéria? Corpo "saco de órgãos"? (CECCIM; CARVALHO, 2005, p. 82) Cabeça, tronco e membros bem alinhavados? Órgãos sensoriais bem afinados? Seria negar a dimensão imaterial do corpo? Negar a dimensão expressiva, comunicativa do corpo? Negar a dimensão intuitiva do corpo? $\mathrm{Ou}$ seria o indício de uma educação corporal limitada, insuficiente, restrita? O indício de que não temos levado a sério a potência das boas experiências corporais na vida das pessoas? Indício de que não temos tornado perceptível que "do corpo nascem e se propagam as significações que fundamentam a existência individual e coletiva; [...] eixo da relação com o mundo, o lugar e o tempo nos quais a existência toma forma? (LE BRETON, 2006, p. 7) Indício de que não temos tornado perceptível que a Educação Física pode potencializar a relação com o mundo?

Os corpos sobre os quais se falava nas conversas formais e informais pareciam ser desprovidos de sexo, cor, forma, peso, idade ou desejo. Falava-se do corpo "humano" de uma forma bastante abrangente e generalizada, sem, no entanto, haver referências às diferenças corporais. Falar sobre o corpo era mencionado, muitas vezes, pelas meninas, como algo difícil, "complicado". Refletir sobre seu corpo de mulher, sobre a forma como ele se expressa, entra em contato com outros corpos e é vivido culturalmente eram aspectos dissociados dos conhecimentos a serem "aprendidos" a respeito do corpo. O conhecimento do corpo e das feminilidades, que nele se constituem e se expressam, não eram identificados pelas meninas como possíveis conhecimentos da educação física e não faziam parte da agenda dessas aulas, que eram diretamente associadas às práticas esportivas e aos jogos ao ar livre, talvez porque suas aulas se restringissem a jogos de vôlei, futebol, handebol, basquete e caminhadas.

O tratamento funcional, utilitário, objetivo do corpo faz parte dos discursos que inauguraram a presença da educação física nas 
instituições escolares no final do século XIX, início do século XX (Soares, 2001) e ainda servem como fundamento para as práticas pedagógicas de muitos de seus profissionais. A Educação Física vem se utilizando, historicamente, de diferentes técnicas corporais (MAUSS, 1974. apud DAOLIO, 1994) para intervir sobre os corpos, criando movimentos, posturas, gestualidades de uma forma bastante prescritiva, baseando-se em estabilidades, certezas e normas. Aprender a executar "corretamente" esses movimentos parece ser um caminho para o não pensar, não perceber, não sentir o processo de movimentar-se e tudo que é experimentado pelo corpo nesse processo. Movimento é corpo que se expressa, é corpo vivo sendo descoberto nas aulas de Educação Física.

Possivelmente, o fato de apenas "praticarem atividades físicas" ao longo de sua vida escolar, conforme as meninas relataram, tenha contribuído para a construção de representações de Educação Física descoladas das questões do corpo e suas múltiplas expressões e coladas às questões esportivas, tema central, prática corporal quase exclusiva das aulas das meninas. O corpo do esporte é muitas vezes um corpo que executa movimentos seguindo regras, limites e desejos externos a ele, corpo que suporta a execução do movimento como se corpo e movimento fossem elementos distintos.

A subjetividade dos corpos parece não ser temática das aulas de educação física, não faz parte do programa. O não pensar sobre os corpos, suas sensações, alegrias, esforços, desprazeres, possibilidades e dificuldades, utilizando a prática mecânica e reprodutora de exercícios ou gestos esportivos como elemento central das aulas, tem ensinado às alunas que a aula de educação física é para praticar exercícios físicos e/ou jogar, não para conhecer, refletir, trocar, interagir ou questionar a respeito do próprio corpo e dos corpos dos outros.

Apesar de reconhecermos socialmente que o corpo é tema da Educação Física, a realidade mostra que o debate sobre o corpo ainda é um tema incomum na Educação Física escolar. A problematização do corpo ainda não foi reconhecida como algo 
visceral para as aulas de Educação Física na escola. Ensinar apenas esportes e jogos ainda é, frequentemente, o limite do seu papel.

Essa fronteira, tradutora de uma cultura escolar que nasceu a partir do desejo de disciplinar os estudantes brasileiros (ISSE, 2003) tem privilegiado a objetivação do corpo em detrimento de sua subjetivação. Essa fronteira torna visível que, apesar dos inúmeros debates acadêmicos e pedagógicos, que questionam essa objetivação e propõem transformações, apesar da crise da modernidade, a nossa "condição de possibilidade" (FOUCAULT, 1995. apud LOURO, 2004) na educação física escolar parece ser essa. Não estamos suficientemente desconfortáveis para abandonarmos a nossa velha história: avaliações, comparações, classificações e normatizações, buscando-se o "conserto" daquilo que é considerado diferente, anormal, pior ou inadequado.

\section{SOBRE ALGUMAS POSSIBILIDADES PARA O ENCONTRO ENTRE EDUCA- ÇÃO FÍSICA E OS ESTUDOS SOBRE O CORPO NA ESCOLA}

O que pode, pois, ser feito para desestabilizar, desarranjar essa tradição das práticas cotidianas da Educação Física na instituição escolar? O que fazer para estranhar os currículos constituídos como verdades culturais? Questionar o que faz parte do currículo pressupõe assumir os riscos da transformação. Estranhar o currículo significa "passar dos limites, atravessar-se, desconfiar [...] e olhar de mau jeito o que está posto; colocar em situação embaraçosa o que há de estável naquele 'corpo de conhecimentos'; enfim fazer uma espécie de enfrentamento das condições em que se dá o conhecimento". (LOURO, 2004, p. 64)

A ideia

É pôr em questão o conhecimento (e o currículo), pôr em questão o que é conhecido e as formas como chegamos a conhecer determinadas coisas e a não conhecer (ou a desconhecer) outras [...] por em questão a ideia de que dispunha de um corpo de conhecimento mais ou menos seguro que deva ser transmitido, bem como por em questão a forma 
usual de conceber a relação professor-estudantetexto (texto aqui tomado de forma ampliada) [...] questionar sobre as condições que permitem (ou que impedem) o conhecimento. Isso remete [...] à ideia de que há limites $^{3}$ para o conhecimento: nessa perspectiva, parece importante indagar o que ou o quanto um dado grupo suporta conhecer ${ }^{4}$. (LOURO, 2004, p.65)

Estranhar o currículo é fazer perguntas. Poderia ser perguntarse por que o corpo, que ocupa lugar central na "teorização social contemporânea" (SANTOS, 2007, p. 84), ainda é discutido de uma forma tão restrita nas escolas? Por que e de que forma tantos corpos, gestualidades e desejos são silenciados ou submetidos nas aulas de Educação Física? Como pode ser que os estudantes sequer percebem que estão estudando o corpo? Quais e por que algumas perguntas não são feitas a respeito do corpo ou não são ouvidas nos espaços escolares? Por que não perguntamos ou ouvimos o que nossos estudantes pensam sobre seus corpos e os corpos dos outros? Por que não confrontamos essas ideias com as representações de corpo que são apresentadas nas mídias? Estranhar o currículo poderia ser reconhecer o corpo, suporte do movimento e lugar onde "tudo se inscreve" (SANTOS, 2007, p. 91), como uma das temáticas mais urgentes e atuais para os debates escolares. Reconhecer que ensinar apenas a respeito do corpo biológico é muito pouco diante de tantos significados culturais que nele se inscrevem.

Se hoje somos capazes de repudiar moralismos, divisões sociais ou discriminações pautadas em diferenças corporais e reconhecemos que o corpo se tornou um "bem" a ser consumido e preservado e tornou-se um assunto que interessa a quase todos, de diferentes e de múltiplas formas, como podemos ignorar a urgência do debate a respeito dele na disciplina que o coloca em evidência o tempo todo?

Falamos tanto que a sociedade contemporânea vive uma crise ética e não nos damos conta, muitas vezes, que a ética e a sensibilidade a essa crise são construídas corporalmente (SANTIN,

${ }^{3,4}$ Grifo da autora.

Movimento, Porto Alegre, v. 17, n. 02, p. 225-237, abr/jun de 2011. 
1995), já que é na pele e pela pele que vivemos nossa humanidade. Há muitas instâncias que ensinam fora da escola, mas esses ensinamentos voltam à escola e lá são muitas vezes reforçados, cristalizados, quando poderiam ser questionados e sofrer rupturas. Trabalhar em regiões de fronteira do corpo mostra a sua plasticidade e torna evidente o corpo como processo. "Não há soluções milagrosas para a sala de aula", o que "não quer dizer, no entanto, que todas as práticas tenham o mesmo efeito". (SANTOS, 2007, p. 88)

Permitamo-nos, pois, estranhar o currículo. Algumas mortes serão necessárias para que a Educação Física siga viva na escola. 
Physical Education class is no place to study the body

Abstract: The present text discusses the understanding of high school students regarding the relations between studying the body and the Physical Education at school. The study is based on observations, semi-structured interviews, dialogues and field diaries, as instruments for collecting data. The results indicate that there is a dissociation between the Physical Education at school and the studies concerning the body. Studying the body is associated to Biology and Science, and to the interventions of the health professionals working at school. There is a biomedical, individualist and hierarchical perspective in relation to the knowledge concerning the body which is considered from a nonhistorical, decontextualized, disciplinary and fragmentary perspective. It problematizes the idea that studying the body is directly associated to learning cares to make it healthy, much more connected to the Health Sciences than to Pedagogy.

Keywords: Body. Knowledge. Physical Education at School.

\section{¿Clase de educación física no es para estudiar el cuerpo?}

Resumen: Este artículo discute la comprensión de los estudiantes de la escuela secundaria sobre la relación entre el estudio del cuerpo y la educación física escolar. El estudio utilizó observaciones, entrevistas semi-estructuradas, diálogos y diario de campo como herramienta para la colecta de informaciones. Los resultados indican que hay una disociación de la educación física en la escuela y los estudios sobre el cuerpo. Estudiar el cuerpo se relaciona con las disciplinas de la biología y las ciencias y con las intervenciones de los profesionales de la salud en la escuela. Hay una perspectiva biomédica, individualista y jerárquica en respeto a los saberes del cuerpo, que se entiende desde un enfoque ahistórico, descontextualizado, disciplinar y fragmentado. Problematiza la idea de que estudiar el cuerpo está directamente relacionado a aprender cuidados que lo hacen más saludable, relacionado mucho más con las ciencias de la salud que con la pedagogía.

Palabras-clave: Cuerpo. Conocimiento. Educación Física Escolar. 


\section{REFERÊNCIAS}

CECCIM, Ricardo B.; CARVALHO, Yara M. de. Ensino da saúde como projeto da integralidade: a educação dos profissionais de saúde no SUS. In: PINHEIRO, Roseni et al (Org). Ensinar saúde: a integralidade e o SUS nos cursos de graduação na área da saúde. Rio de Janeiro: IMS/UERJ: CEPESQ: ABRASCO, 2005.

DAOLIO, Jocimar. Da cultura do corpo. Campinas, SP: Papirus, 1994.

ISSE, Silvane F. Corpo e feminilidade: um estudo realizado com meninas adolescentes no contexto da educação física escolar. 162 f. Dissertação (Mestrado) - Escola de Educação Física, Universidade Federal do Rio Grande do Sul, Porto Alegre, 2003.

LE BRETON, David. A sociologia do corpo. Petrópolis, RJ: Vozes, 2006.

LOURO, Guacira L. Um corpo estranho: ensaios sobre sexualidade e teoria queer. Belo Horizonte: Autêntica, 2004.

LUPTON, Deborah. Corpos, prazeres e práticas do eu. Educação e Realidade, Porto Alegre, v.25, n.2, p.15-48, jul./dez. 2000.

SANTIN, Silvino. Educação física: ética, estética, saúde. Porto Alegre: EST, 1995.

SANTOS, Luís H. S. dos. O corpo que pulsa na escola e fora dela. In: RIBEIRO, Paula R. C. et al (Org.). Corpo, Gênero e Sexualidade: discutindo práticas educativas. Rio Grande, RS: Editora da FURG, 2007.

SOARES, Carmen L. Educação Física: raízes europeias e Brasil. Campinas, SP: Autores Associados, 2001.

Endereço para correspondência:

Silvane Fensterseifer Isse

Rua Piauí, 1008 -

Lajeado/RS -

CEP 959000-000

Recebido em: 18.04.2011

Aprovado em: 16.05.2011 
